ORIGINAL ARTICLE

\title{
New height, weight and head circumference charts for British children with Williams syndrome
}

\author{
N D T Martin, W R Smith, T J Cole, M A Preece
}

Arch Dis Child 2007;92:598-601. doi: 10.1136/adc.2006.107946

See end of article for authors' affiliations

Correspondence to:

Dr Neil Martin, Children's

Assessment Centre, Kent and Canterbury Hospital, Ethelbert Road, Canterbury CT1 3 NG, UK.

neil.martin@ekht.nhs.uk

Accepted 22 January 2007

Published Online First

14 February 2007
Aim: To produce a growth reference for British children with Williams syndrome.

Methods: The children and adults recruited into the study were all affiliated to the Williams Syndrome Foundation, a parent support group founded in 1979. They have all been shown to have a deletion of chromosome 7q11.23. One growth nurse (WRS) prospectively measured the weight, height and head circumference of individuals from 19 regions in Great Britain including Scotland, England and Wales. 169 children and adults were measured on up to four occasions between 2001 and 2004 (275 measurements). In addition, retrospective data were obtained from the hospital notes of 67 of these individuals (586 measurements). Centile curves were constructed using Cole's LMS method.

Results: The centile charts differ from charts previously derived in the USA and Germany and provide more appropriate standards for the British population.

Conclusions: We propose that these charts be adopted for routine clinical practice as abnormalities in growth are an important feature of this syndrome.
$\mathrm{S}$ hort stature is a recognised feature of Williams syndrome. This syndrome was first described in 1961 as a triad of supravalvular aortic stenosis, learning difficulties and unusual facial features. ${ }^{1}$ It was quickly recognised as being linked with infantile hypercalcaemia and in 1993, Ewart et al demonstrated the presence of a micro deletion on chromosome 7 (del 7q11.23) in all children with this syndrome. ${ }^{2}{ }^{3}$ To date, 28 genes have been detected within this region, including the elastin gene. The genes responsible for the developmental abnormalities and hypercalcaemia remain to be determined. A number of large cohort studies have described the presence of low birth weight, failure to thrive in infancy, short stature and precocious puberty. ${ }^{4-6}$ In addition to congenital heart disease and infantile hypercalcaemia, children with Williams syndrome have been described as having hypothyroidism, ${ }^{7}$ growth hormone insufficiency ${ }^{8}$ and coeliac disease. ${ }^{10}$ These diverse conditions make accurate assessment of growth an essential requirement of health surveillance.

Morris et al produced growth charts for children with Williams syndrome in 1988 from retrospective, cross-sectional data collected from American children attending either their

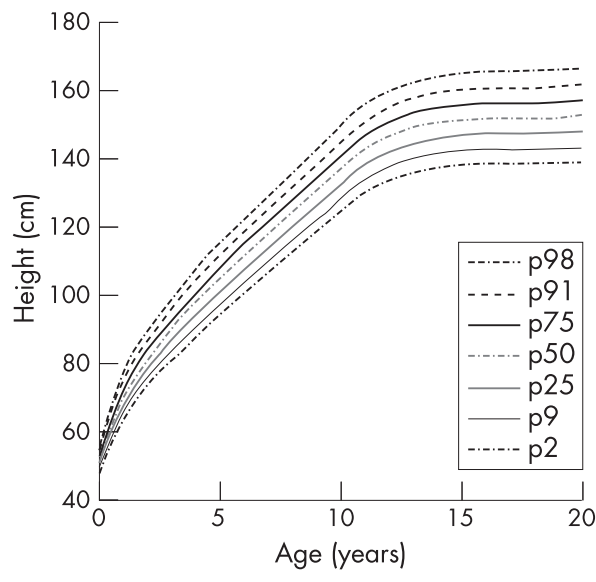

Figure 1 Height chart for females with Williams syndrome. clinic in Salt Lake City, Utah or a Williams Syndrome National Association meeting in $1986 .{ }^{11}$ The mean adult heights of males and females were 167 and $157 \mathrm{~cm}$, respectively. Pankau et al published retrospective data from a cohort of German children with Williams syndrome and in this population mean adult heights for males and females were 168 and $154 \mathrm{~cm}$, respectively. ${ }^{12}$ Both these studies were published before the gene deletion had been identified. Partsch et al subsequently documented a prospective study of a cohort of the same German children in 1999 but again the diagnosis was only confirmed genetically in $44 \%$ of cases. ${ }^{6}$ Mean adult heights for this cohort of males and females were 165 and $152 \mathrm{~cm}$, respectively. The most recent British data were published by Martin et al in 1984 and in that cohort mean adult heights for males and females were 159 and $147 \mathrm{~cm}$, respectively. Therefore, we identified the need for a contemporary British growth reference for children with genetically diagnosed Williams syndrome. ${ }^{4}$

\section{METHODS}

The study was approved by the South Thames Multicentre Research Ethics Committee and local ethics committees. Individuals were affiliated to the Williams Syndrome

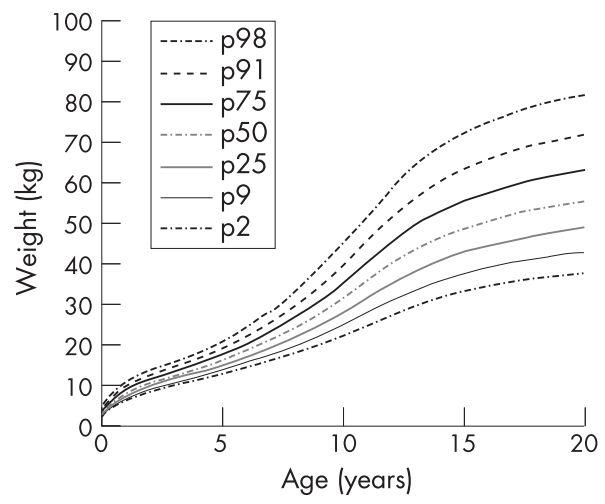

Figure 2 Weight chart for females with Williams syndrome. 


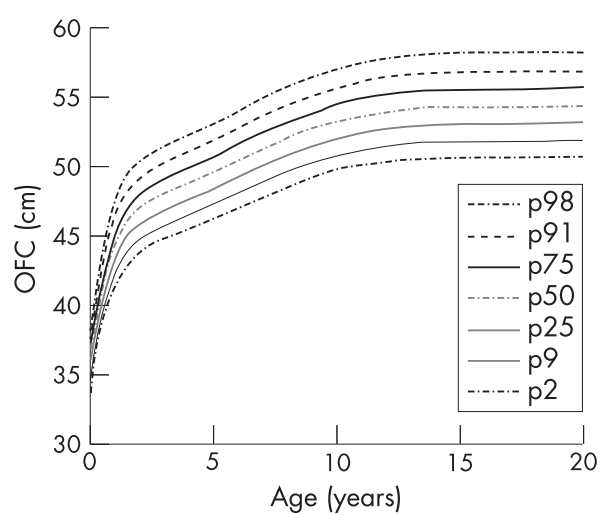

Figure 3 Head circumference chart for females with Williams syndrome.

Foundation, the UK parent support group (www.williamssyndrome.org.uk). Written consent was obtained to measure children with Williams syndrome at intervals, obtain blood for chromosome analysis as necessary and review available hospital records.

Adults (age $>20$ years) were measured once. Children were measured between one and four times between January 2001 and December 2004. A brief medical history was obtained. No individuals had been treated with growth hormone. Five children had been treated with thyroxine, but only three remained on medication. Three individuals had been diagnosed with diabetes mellitus, including two adults with late onset non-insulin dependent diabetes. Genetic status was confirmed either from the hospital records or from the appropriate cytogenetic laboratory. The methods used were either the Vysis (Abbot Molecular, Des Plaines, IL, USA; ELN-, LIMK-, D7S613-) or Oncor (Gaithersburg, MD, USA; D7S427-) probe. Where no record was available, consent for blood letting was obtained and samples were analysed in the Academic Unit of Medical Genetics, Manchester using the Vysis probe (M Tassabehji, personal communication).

\section{Measuring techniques}

WS performed all prospective height measurements using a Leicester stadiometer (Crawlea Medical, Birmingham, UK) and the non-stretch technique. Individuals wearing light clothing and without footwear were electronically weighed using Tanita THD-305 scales (Tanita, Yiewsley, Middlesex, UK). Head circumferences were measured with the Lasso-O tape measure (Child Growth Foundation, London, UK). Retrospective data

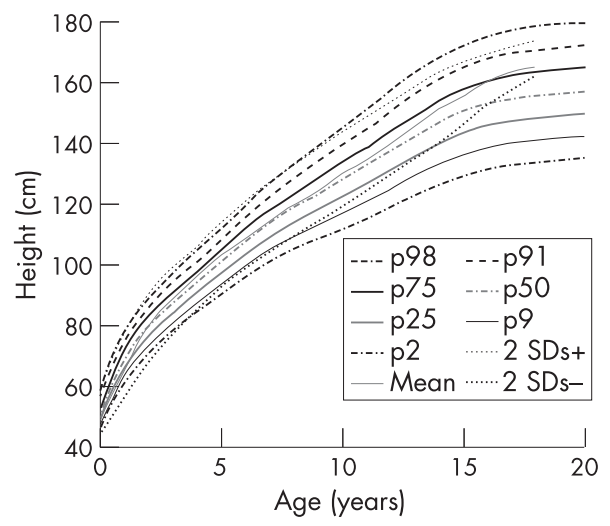

Figure 4 Height chart for males with Williams syndrome (p2-p98) with that of Morris et al superimposed (mean \pm 2 SDs). ${ }^{11}$

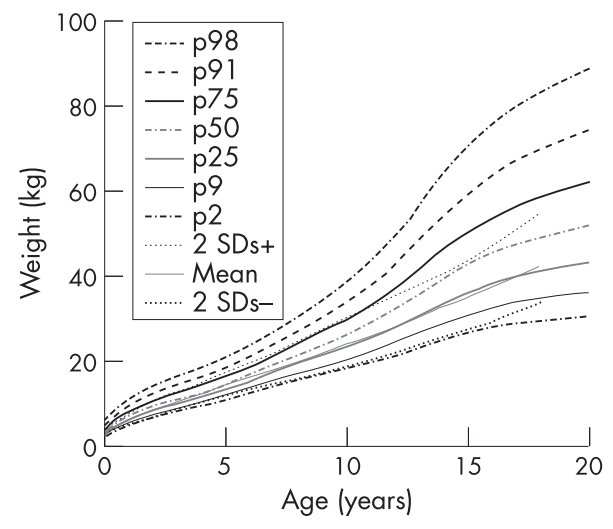

Figure 5 Weight chart for males with Williams syndrome (p2-p98) with that of Morris et al superimposed (mean \pm 2 SDs). ${ }^{.1}$

would have been collected using variable techniques with standard child surveillance equipment.

\section{Excluded children}

A list of 615 children and adults was obtained from the Williams Syndrome Foundation. A total of 219 children or adults consented to take part in the study. Measurements were obtained and chromosomal deletion confirmed in 169 subjects (86 male and 83 female).

\section{Statistical analysis}

Plots of height, weight and head circumference were used to identify gross errors, which were compared to the original forms and transcription errors corrected. Centile curves were fitted to the data using Cole's LMS method. ${ }^{13}$ This assumes that the data can be transformed to normality by a suitable power transformation (L) and the distribution is then summarised by the median (M) and coefficient of variation (S). The values of $\mathrm{L}$, $\mathrm{M}$ and $\mathrm{S}$ are constrained to change smoothly with age and the fitted values can be used to construct centile curves. Centiles were constructed using the nine centile curves as described by Cole. ${ }^{14}$ Centile lines are placed exactly two thirds of an SD score apart leading to the current 2, 9, 25, 50, 75, 91, 98 pattern.

\section{RESULTS}

Table 1 lists the frequencies of measurement by age. Of the 861 measurements, 275 were prospectively collected and the remaining 586 were retrospective. The numbers of measurements by sex (male/female) were as follows: weight 417/394, height 387/354 and head circumference 160/135. Centile charts

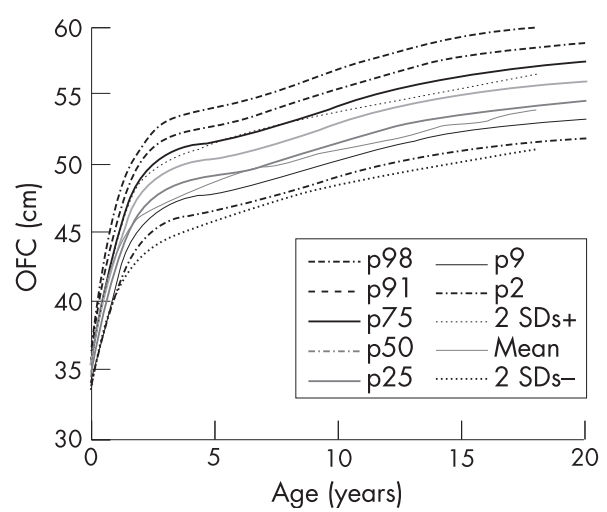

Figure 6 Head circumference chart for males with Williams syndrome (p2-p98) with that of Morris et al superimposed (mean \pm 2 SDs)." 


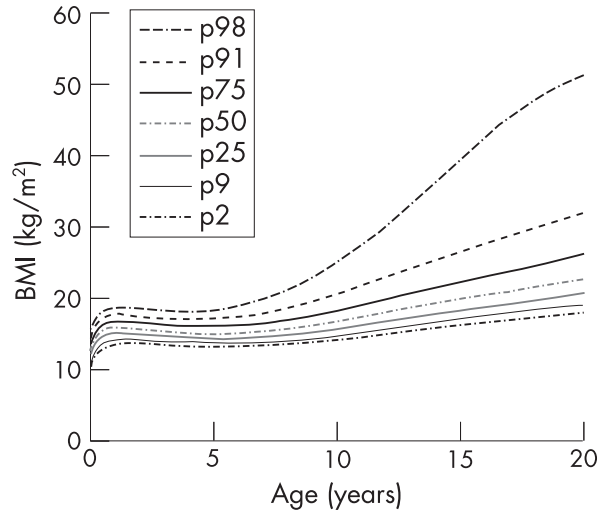

Figure $7 \quad B M I$ chart for females with Williams syndrome (p2-p98).

for female height, weight and head circumference are shown in figs 1-3. Centile charts for male height, weight and head circumference are superimposed on those of Morris et al in figs $4-6 .{ }^{11}$ Centile charts for female and male body mass index (BMI) are shown in figs 7 and 8 .

\section{DISCUSSION}

We have produced the first British growth charts for Williams syndrome and the first charts where the genetic status of all individuals has been confirmed. Mean heights for adult males and females with Williams syndrome were 159 and $152 \mathrm{~cm}$, respectively. Thus, they are on average 18 and $12 \mathrm{~cm}$ shorter than reference British adult males and females. ${ }^{15}$ These mean heights are similar to previous data of Morris et al, but the growth curves are significantly different with, in particular, wider centile ranges for male heights and weights. Head circumferences in both males and females were $1-2 \mathrm{~cm}$ greater across all ages from 2 to 18 years.

The short stature in Williams syndrome can be accounted for by (a) restricted growth prenatally, (b) failure to thrive in infancy, (c) restricted growth in childhood and (d) precocious puberty. Kyphoscoliosis may make height measurement difficult and it is unlikely that congenital heart disease restricts growth in most cases. ${ }^{411} 12$ Rarely other diseases have been reported to impair growth and the use of these charts may aid diagnosis and management. Thus, there at are least two published reports of growth hormone insufficiency in association with Williams syndrome. ${ }^{8} 9$ In addition, the KIGS database, a voluntary database of growth hormone prescribers, identifies 19 cases of Williams syndrome treated with growth hormone between 1986 and 2000 (M Mistry, personal communication). Abnormal thyrotrophin and thyroid hormone secretion has been reported in a number of case reports and dysgenesis of the thyroid gland may be associated with the syndrome. ${ }^{76}$ Premature activation of the hypothalamic-pituitary-gonadal axis is now recognised both in this syndrome and other conditions associated with learning difficulties. ${ }^{17-19}$ Finally, a number of authors have suggested that coeliac disease is more common in Williams syndrome, although preliminary data from this study do not confirm these observations. ${ }^{10} 20$

Concerns were raised by the first British cohort study that obesity might be more prevalent, particularly in adult life. ${ }^{4}$ Furthermore, obesity has been noted in the knock-out mouse model for Williams syndrome ( $\mathrm{M}$ Tassabehji, personal communication). Other authors have described the opposite. Kaplan et al in a small series demonstrated decreased percentage body fat in four out of six individuals studied. ${ }^{21}$ Pankau et al analysed data from his longitudinal study of growth in Williams syndrome and demonstrated lower BMI in infancy and early childhood in both

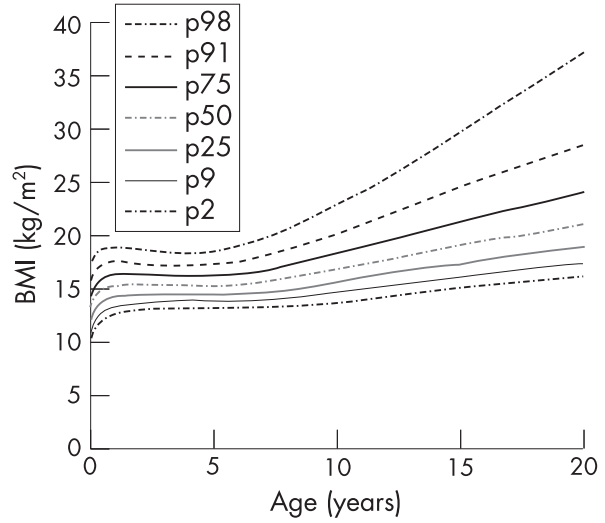

Figure 8 BMI chart for males with Williams syndrome (p2-p98).

males and females, increasing in adult life towards the mean. ${ }^{22}$ He did not detect significant obesity.

Calculating BMI values for both males and females from this cohort and comparing them with current British centile curves ${ }^{23}$ confirms Pankau's findings that obesity is not prevalent in childhood or adolescence but may develop in adult life. It is likely that activity levels and diet are the main predisposing factors, but other metabolic determinants may be important. ${ }^{21}$ Whatever the explanation, any tendency to develop obesity and possible insulin resistance with the precedent of prenatal growth restriction would be of concern, particularly given the frequent association of supravalvular aortic stenosis, hypertension and an abnormal vascular tree. ${ }^{24} 25$ In this cohort 14 individuals were being treated for hypertension and two for type 2 diabetes.

\section{CONCLUSION}

Charts have been produced which are appropriate for British children with Williams syndrome. Growth surveillance throughout childhood will enable coexistent growth disorders to be detected. Guidance on other aspects of health surveillance for children and adults with Williams syndrome is available from the Williams Syndrome Foundation (www.williamssyndrome.org.uk).

\begin{tabular}{llll}
$\begin{array}{l}\text { Table } 1 \\
\text { sex }\end{array}$ & \multicolumn{3}{l}{ Frequencies of measurement by age and } \\
\hline Age (years) & Male & Female & Total \\
\hline 0 & 44 & 49 & 93 \\
1 & 35 & 31 & 66 \\
2 & 38 & 31 & 69 \\
3 & 37 & 39 & 76 \\
4 & 35 & 31 & 66 \\
5 & 30 & 27 & 57 \\
6 & 31 & 25 & 56 \\
7 & 34 & 22 & 56 \\
8 & 21 & 22 & 43 \\
9 & 20 & 19 & 39 \\
10 & 15 & 14 & 29 \\
11 & 12 & 15 & 27 \\
12 & 16 & 13 & 29 \\
13 & 11 & 9 & 20 \\
14 & 11 & 15 & 26 \\
15 & 9 & 8 & 17 \\
16 & 2 & 7 & 9 \\
17 & 3 & 7 & 10 \\
18 & 5 & 1 & 6 \\
19 & 2 & 5 & 7 \\
$20+$ & 29 & 31 & 60 \\
Total & 440 & 421 & 861 \\
\hline & & & \\
\hline
\end{tabular}




\section{What is already known on this topic}

- Williams syndrome affects growth in a number of ways.

- The most recent British height data for children with Williams syndrome were produced in 1984.

\section{What this study adds}

- New growth charts for British children with Williams syndrome.

- Improved ability to monitor growth and potential treatments in Williams syndrome.

\section{ACKNOWLEDGEMENTS}

We would like to thank the Williams Syndrome Foundation for funding this project and for the help of all the families involved. We would also like to thank May Tassabehji for genetic testing and advice and John Short and his team at Harlow Printing for steering the final production of the growth charts.

\section{Authors' affiliations}

N D T Martin, W R Smith, East Kent Hospitals NHS Trust, Canterbury, Kent, UK

T J Cole, M A Preece, UCL Institute of Child Health, London, UK

Pharmacia and Pfizer UK provided generous financial support.

Competing interests: None.

Copies of the A4 charts and PCHR inserts are available from Harlow Printing, Maxwell Street, South Shields, Tyne and Weir NE33 4PU, UK or from the Williams Syndrome Foundation.

\section{REFERENCES}

1 Williams JCP, Barratt-Boyes MB, Lowe JB. Supravalvular aortic stenosis. Circulation 1961:24:1311-8.
2 Black JA Bonham-Carter RE Association between aortic stenosis and cases of severe infantile hypercalcaemia. Lancet 1963;ii:745-9.

3 Ewart AK, Morris CA, Atkinson D, et al. Hemizygosity at the elastin locus in a developmental disorder, Williams syndrome. Nat Genet 1993;5:11-16.

4 Martin NDT, Snodgrass GJA, Cohen RD. Idiopathic infantile hypercalcaemia - a continuing enigma. Arch Dis Child 1984;59:605-13.

5 Jones KL, Smith DW. The Williams elfin facies syndrome. A new perspective. J Pediatr 1975;86:718-23.

6 Partsch CJ, Dreyer G, Gosch A, et al. Longitudinal evaluation of growth, puberty and bone maturation in children with Williams syndrome. J Pediatr $1999 \cdot 134: 82-9$

7 Bini R, Pela I. New case of thyroid dysgenesis and clinical signs of hypothyroidism in Williams syndrome. Am J Med Genet 2004;127A:183-5.

8 Spadoni GL, Colloridi V, Finocchi G, et al. Williams syndrome and growth hormone deficiency. J Pediatr 1983;102:640.

9 Kuijpers GM, De Vroede M, Knol HE, et al. Growth hormone treatment in a child with Williams-Beuren syndrome. Eur J Pediatr 1999;158:451-4

10 Giannotti A, Tiberio G, Castro $M$, et al. Coeliac disease in Williams syndrome. $J$ Med Genet 2001;38:767-8.

11 Morris CA, Demsey SA, Leonard CO, et al. Natural history of Williams syndrome: physical characteristics. J Pediatr 1988;113:318-26.

12 Pankau R, Partsch CJ, Gosch A, et al. Statural growth in Williams-Beuren syndrome. Eur J Pediatr 1992;151:751-5.

13 Cole TJ, Freeman JV, Preece MA. British 1990 growth reference centiles for weight, height, body mass index and head circumference fitted by maximum penalized likelihood. Stat Med 1998;17:407-29.

14 Cole TJ. Do growth chart centiles need a face lift? BMJ 1994;308:641-2.

15 Freeman JV, Cole TJ, Chinn S, et al. Cross sectional stature and weight reference curves for the UK, 1990. Arch Dis Child 1995;73:17-24.

16 Cammareri V, Vignati G, Nocera G, et al. Thyroid hemiagenesis and elevated thyrotrophin levels in a child with Williams syndrome. Am J Med Genet 1999;85:491-4.

17 Southorn DJ, Butler MG. How common is precocious puberty in patients with Williams syndrome? Clin Dysmorphol 1997;6:91-3

18 Cherniske EM, Sadler LS, Schwartz D, et al. Early puberty in Williams syndrome. Clin Dysmorphol 1999;8:117-21.

19 Merke DP, Cutler GB. Evaluation and management of precocious puberty. Arch Dis Child 1996:73:317-24.

20 Santer R, Pankau R, Schaub J, et al. Williams-Beuren syndrome and celiac disease. J Pediatr Gastroenterol Nutr 1996;23:339-40.

21 Kaplan AS, Stallings VA, Zemel BS, et al. Body composition, energy expenditure and energy intake in patients with Williams syndrome. J Pediatr 1998;132:223-7.

22 Pankau R, Partsch CJ, Neblung A, et al. Natural history of body mass index in Williams-Beuren syndrome. Am J Med Genet 1994;52:51-4.

23 Cole TJ, Freeman JV, Preece MA. Body mass index reference curves for the UK 1990. Arch Dis Child 1995:73:25-9.

24 Sadler LS, Gingell R, Martin DJ. Carotid ultrasound examination in Williams syndrome. J Pediatr 1998;132:354-6.

25 Kalbhenn T, Neumann LM, Lanksch WR, et al. Spontaneous intracerebral haemorrhage and multiple infarction in Williams-Beuren syndrome. Pediatr Neurosurg 2003;39:335-8. 